\title{
Living Within Our Limits: A Defense of the Fall
}

\author{
Adam Green \\ Azusa Pacific University \\ Joshua Morris \\ Azusa Pacific University
}

\begin{abstract}
A doctrine of the fall does important theological work, both theodical and soteriological. Many, however, have found it hard to square with evolutionary history in a way that would still allow the doctrine to do that theological work. In this essay, we use insights from the biology of pain and from Augustine's views on death to give a defense of a fall that is friendly to an evolutionary framework and is deeply consonant with the story of the Fall in Genesis interpreted mythologically. In pursuing this defense, we are put in a better position to understand the moral and spiritual import of our experience of pain and mortality.
\end{abstract}

\section{I}

It doesn't take a lot of imagination anymore to see how God could have created the world through something like guided evolution, but what about the Fall? That is, what about the idea that at the dawn of our species the moral innocence of humanity was exchanged for a human condition that disposes us to sin and that we experience suffering and death as a result? More simply, one might think of the Fall as associated with "the nonessential entrance of sin into the created order by way of human volition," (Patriquin 2019, 174) where this entrance is a matter of historical events that predate the human condition as we experience it.

It seems like we need a doctrine of the Fall and for two reasons-theodical and soteriological. ${ }^{1}$ Our world is full of evil, suffering, and pain. The problem of evil is hard enough if all we must do is explain why God allows these things. Without the Fall, it looks like we must explain not only why God allows evil but why it appears to be an intrinsic part of the world God chose to create. In this article, drawing on insights from the biology of pain, we mount a defense of the Fall narrative of Genesis as an apt myth for a biologically feasible series of events that can fulfill the theodical and soteriological function of the Fall.

${ }^{1}$ McFarland 2010 very usefully brings out these two distinct dimensions to the doctrine, though the two aspects are certainly implicit in other perceptive assessments of the stakes of the debate (cf. Smith 2017).

Journal of Analytic Theology, Vol. 8, August 2020

$10.12978 /$ jat.2020-8.061713121418

(C) 2020 Adam Green, Joshua Morris • (C) 2020 Journal of Analytic Theology 
To be sure, the Fall narrative of Genesis didn't "solve" the problem of evil. We are told that a man and a woman ate a forbidden fruit at the behest of a serpent and that now, as a consequence, the world is broken. This introduces new questions such as, "Why would God create a universe so fragile that a couple of hominids could break the entire created order?" (cf. Murray 2008, 82) or "What possible motivation would a creature in an all good creation have for sinning?" ${ }^{2}$ Just as the story of creation clearly communicates that this is God's world, the story of the Fall is supposed to communicate that what is bad about our world is not God's fault. The story may provoke further questions, but it answers the most fundamental question definitively. This is God's world, but not everything about this world is reflective of the God who made it. Only the good is of God, not the bad. Without some such story, the worry is that we are left with a vision of God as someone who creates pain, suffering, and vice rather than someone who creates good creatures who have the capacity to change the world for the worse. It isn't clear why a God who creates evil would be either good or worthy of worship.

There is another related but distinct function which the Fall plays in the Christian story because we must also explain the universality of the human condition. Every human irrespective of their nation, tongue, or time of history has the moral cancer of the race of Adam growing within them and is in need of the divine grace which alone can cure it. The bad press that hard-core Augustinian views sometime receive when it comes to total depravity and original sin can obscure the fact that these more Reformed views are one way of spinning something that is ubiquitous across the Christian tradition, namely, the idea that the fall of Adam and Eve is a necessary part of the explanation of what Ian McFarland calls humanity's "solidarity in sin" (cf. McFarland, chapter 6). There must be something wrong with us, with all of us, in order to make sense of the atonement, and it must somehow affect every human being despite differences in culture, race, sex, and gender. To be sure, original sin and the Fall are distinct topics. The idea, however, that we all descend from a first couple who somehow ingested a spiritual poison that can be passed down the human generations is a very useful way of explaining the universal need for salvation. It fits with our experience of how one generation can either benefit or harm the next, and it simplifies our picture of the fall of the species by positing a time when the species consisted of exactly two people who could undergo a single event.

Thus, there are at least two functions that a doctrine of the Fall serves that would be difficult to account for without recourse to a story with the same basic form as the Fall of Genesis. It would be a huge loss theologically, for instance, to part with the idea that a state of innocence was violated by a prior person or persons which then created the human condition in which all descendants are alienated from God, each other, nature, and ourselves making it the case that we are all in need of divine restoration. However apt the imagery that is used, it is that basic theological truth that would appear to be hard to do without. One could be forgiven, however, for

\footnotetext{
${ }^{2}$ Although Augustine is more widely associated with the topic of original sin, he very clearly articulates the problem of the primal sin as well. He somewhat scandalously eliminates all possible sources for the sin of Satan and asserts that the very first sin had no efficient cause (Augustine 347; Cf. MacDonald 1998).
} 
supposing that evolution puts that claim in jeopardy. From an evolutionary perspective, life has been on this planet for a long time and death with it. Species after species has struggled to emerge and propagate itself only to be swallowed up by the depths of time. Consequently, it looks like the consequences associated with the Fall - predation, death, severe pain, the struggle to get enough food to survive-have pre-dated our species. This evolutionary consideration seems to undercut the theodical aspirations of a doctrine of the Fall and the ability of the Genesis narrative to make good on those aspirations.

What of the soteriological ones? Genetic research and existing models of speciation tell against the existence of a literal Adam and Eve. Instead current evolutionary models suggest that modern humans descended from an ancestral population that resided in Africa roughly 200,000 years ago (Ruse \& Travis 2009; Stringer 2003; Noonan 2010; Schlebusch et al 2017). As it is believed that Homo sapiens either evolved directly from a communal group of Homo heidelbergensis or via Homo rhodesiens, research in the area would strongly suggest that humans did not evolve from a single couple. Rather, it is believed that Homo sapiens emerged from a small bottleneck population within the ancestral population that began to selectively breed and then eventually migrate out of Africa (Ruse \& Travis 2009; Stringer 2003; Noonan 2010; Schlebusch et al 2017). If there was no first couple from which the rest of us descend, if, for instance, the smallest bottleneck consisted of 10,000 persons, then one might well wonder how we all came to have a "solidarity in sin". To sharpen the worry by putting the two theological functions of the Fall together, if the smallest bottleneck of the species was not very small at all, how could the human race come to suffer universally in virtue of a single human choice? Isn't it more plausible, one might suppose, that the human condition we all share is a function of factors beyond our ancestors' control, factors that, if anything, point to God as the culprit, not us?

In the following sections, we will be presenting a defense of the Fall using the Genesis narrative understood as a mythological depiction of a literal fall. This defense is motivated by both biology and the Christian tradition. We will be using resources from both the biology of pain and the connection in the Christian tradition between physical and spiritual death to explore the possibility of a kind of literal fall depicted in mythological fashion by the Genesis narrative.

Before we get to the first stage of this defense, it is worth making a couple remarks about the scope of the project. First, it is worth emphasizing that what we are offering is a defense in the sense used in the problem of evil literature. We don't claim to know the truth about, as Milton famously put it to open Paradise Lost, "man's first disobedience...whose mortal taste brought death into the world and all our woe." We only seek to tell a story, not without some support, that would allow the depiction of a Fall in Genesis to do its theodical and soteriological work as an apt myth for a different kind of literal fall.

Second, we would emphasize what this defense is a defense of. It is a defense of the Fall. It is not an attempt to solve the problem of evil in general nor will it try to solve the more circumscribed problems of animal pain or the origin of sin. What is said will have some bearing on these issues, but this essay in no way is meant to be a solution to such problems. Instead, what it seeks to address is all and only the following problem. The doctrine of the Fall is an important part of the Christian story 
with an important job description, but one might, for evolutionary reasons, think it incapable of carrying out that job anymore. We will be arguing, on the contrary, that there is a resonance between the biological differences between different kinds of pain and how Augustine teaches us to think about the relationship between our spiritual and physical state. The next section will consider the different kinds of pain and their biological function. Then, we will be in a position to tell a story about how the Fall in Genesis 3, taken as myth, could be an apt way of depicting a literal fall capable of doing meaningful theodical and soteriological work.

\section{II}

The first step in our defense requires looking at human pain through the lens of biology.

From a biological point of view, pain is a very complex phenomenon that is found throughout the animal kingdom. The extensive research on pain suggests that there are three biologically dissociable levels of pain (Sneddon 2014; Bateson 1991). The first type of pain, nociception or better "mere nociception," might not need to be experienced at all. Nociception is a kind of reflexive response to stimuli to which a majority of basal organisms are subject. It is thought that this reflexive response to a noxious stimulus need not even be cognitive in nature (Sneddon 2014; Smith \& Lewan 2009). Nociception is caused by encountering something that has the ability to cause harm to an organism (Sneddon 2014; Bateson 1991; Smith \& Lewan 2009). The result is an embodied negative appraisal typically manifested by withdrawal from the stimulus. Nociception is not unique to simpler organisms but rather is the biological common denominator amongst all creatures who have biological pain.

In each case of nociception, activation of sensory neurons (nociceptors) leads to a series of nerve impulses that ultimately arrive in the central nervous system (CNS). The CNS then processes the signals, sometimes in the matter of milliseconds, and then directs muscles to move in a coordinated response (Bateson 1991; Smith \& Lewan 2009). In so-called "lower organisms," this response may be as simple as moving away from a noxious stimulus (Sneddon 2014; Bateson 1991). However, in higher organisms, the response might be multi-track and conditional, as in a fight or flight response. Similarly, endogenously generated nociception, such as cases of inflammatory or pathological pain, often induce behaviors very different from exogenously stimulated nociception, engaging in rest and self-care rather than flight or fight.

Some species, of course, demonstrate learned avoidance behavior toward a stimulus anticipated to be negative (Sneddon 2014; Bateson 1991; Smith \& Lewan 2009; Rutherford 2002; Broom 2001). In these cases, the organism is not only exhibiting a reflexive response to pain, but also demonstrating a level of cognitive engagement with the sensory experience (Sneddon 2014; Bateson 1991). This signals the transition to the second type of pain that can be differentiated from a purely biological point of view, namely, pain that requires one to posit at least a representation if not a subjective experience of pain in the organism such that it can elicit more complicated anticipatory pain avoidance or management behaviors. 
Organisms that are capable of engaging with pain in this second way possess nociception, but that nociception is taken up in further processing by more intricate brain structures, which then allows for complex behavioral responses that include learning in response to pain. Positing some level of cognitive engagement seems necessary to consider the behavior a true pain response, and this second kind of pain puts more pressure on theorists to posit pain experiences in non-human organisms that are at the least strongly analogous to those found in humans (Sneddon 2014; Bateson 1991).

The third kind of pain that is differentiable from a biological point of view consists not simply in the capacity to anticipate pain but to project it, and this third kind of pain appears to be the unique provenance of human beings in quantity if not also quality. Humans stand out in their ability not only to sense, respond to, and learn from painful experiences, but also in their ability essentially to create physical pain from psychologically traumatic experiences (Ruse \& Travis 2009; Schlebusch et al 2017). Again, this is not to say that human beings are the only organisms that ever experience pain in this third sense. Rather, it is to say that the frequency, variety, and intensity of this third level of pain in human beings is distinctive. The type of pain experience that an organism undergoes seems to be inextricably tied to the complexity of its CNS (Sneddon 2014; Bateson 1991; Broom 2001). This correlation is interesting when considering the origin and purpose of pain in the animal kingdom, namely, to act as a biological limiting system. The thought with this third level of pain, once again, is not that it exists in isolation from the first two levels, but that it takes up those first two levels and adds extra dimensions to pain's biological function(s).

From an evolutionary perspective, both the first and second level of pain seem to be straightforwardly adaptive as each allows an organism to respond to threats so as to promote self-preservation and help the organism avoid further injury if an injury has occurred (Sneddon 2014; Bateson 1991; Smith \& Lewan 2009; Rutherford 2002; Broom 2001). While processes such as attraction to positive environments and avoidance of noxious substances are seen in even primitive uni-cellular organisms (i.e., bacteria, which lack nerves let alone a CNS), the rate of response and the ability to learn avoidance behaviors is severely limited (Sneddon 2014; Bateson 1991). Thus, nociception and behavioral responses to it seem to evolve concurrently with the development of multi-cellularity in the animal lineage as coordinated perception, sensation, and locomotion become essential, especially as organisms move toward specialization of cellular function (i.e., muscle cells for movement and neurons for sensation and conduction of messages) (Sneddon 2014; Bateson 1991; Smith \& Lewan 2009; Broom 2001).

While it is unclear exactly which organisms have pain experiences or precisely when it would have arisen in the tree of life, organisms as primitive as cnidarians (i.e., jellyfish) have reflexive reactions when poked (away from the point of touch) that are controlled by a central nerve net (Smith \& Lewan 2009). They also have the ability to positively respond to stimuli and move toward sources of food (Smith \& Lewan 2009). While these types of simple responses are common throughout invertebrate phyla, the Cephalopod class of Molluscs (i.e., cuttlefish, squid, and octopus) and Crustaceans (i.e., crabs and shrimp) seem to have much more sophisticated behaviors in response to nociception, suggesting a heightened sensation and awareness of it. In 
these organisms, protection of and extensive care for areas of damaged tissue have been observed (Crook, Hanlon, \& Walters 2013; Walters 2018; Alupay, Hadijsolomou, \& Crook 2014; Crook et al 2011). In addition, octopi have been observed to have an increased rate of retreat and defensive ink squirting when touched near a wound (Alupay, Hadijsolomou, \& Crook 2014).

Like Cephalopods and Crustaceans, vertebrates also have developed very complex behaviors in response to nociception. In addition to showing care for areas of the body that have been damaged, many vertebrates (and possibly some invertebrates) alter their behavior in response to repeated encounters with a potentially harmful stimulus (Walters 2018). In mammals, alterations to behavior can include attempts to balance attainment of positive rewards with avoidance of negative stimuli. These learning behaviors (including threat avoidance) in response to nociception have led many scientists to attempt to differentiate pain from nociception suggesting that pain has a necessary affective component. On this model, avoidance learning would suggest at least some level of consciousness and selfawareness, indicating a basic degree of emotive response (Sneddon 2014; Bateson 1991; Rutherford 2002; Broom 2001).

As noted previously, humans have the ability to experience pain in multiple ways that are difficult to find analogs for in other animals (Sneddon 2014; Bateson 1991). Humans have the ability to classify pain based upon its duration, pattern of occurrence, and intensity. These classifications, however, seem to be to an extent individual and subjective. For instance, experiments that have exposed different individuals to identical levels of, say, an electric shock have yielded different reported levels of pain. Examples of complex and difficult to describe pain sensations such as phantom pain and allodynia also stand out as biologically distinctive (Kooijman et al 2000; Limakatso 2019; Jensen \& Finnerup 2014). Phantom pain is common among amputees and is the condition where pain is felt in a region of the body that is no longer attached to the body or neurally connected to the CNS (Kooijman et al 2000; Limakatso 2019). Allodynia is a condition where pain is experienced in response to a stimulus that is not considered noxious (and normally painless) (Jensen \& Finnerup 2014). Psychogenic or somatoform pain has also been reported among those who have experienced emotional trauma. The origin, intensity, and duration of the pain seems to be tied to psychological and behavioral mechanisms rather than standardized physical mechanisms. Reports have also suggested that humans have the ability to undergo episodes of pain asymbolia (a lack of pain) during periods of intense stimulation such as in participation in sporting events or war (Nagasako, Oaklander, \& Dworkin 2003). Individuals have been identified who lack the ability to feel pain at all. Known generally as a congenital insensitivity to pain, individuals can be born with nervous system abnormalities that prevent either the sensation or recognition of pain (Nagasako, Oaklander, \& Dworkin 2003). Likewise, humans can seek out seemingly unnecessary kinds or degrees of biological pain due to the mediation of how an organism relates to the pain psychologically.

The fact that human pain can be studied in ways that the pain of other organisms cannot always poses a threat to claims that any particular kind of pain experience is unique to human beings. We rest on firmer ground in terms of the big picture, however. That bigger picture is this. The cognitive complexity of human 
beings allows human beings to take up nociception and learned avoidance strategies that might have a basic affective element to them into a more cognitively flexible and psychologically mediated classification and projection of pain onto human experiences. This more unique relationship with pain can be biologically adaptive no doubt, but it can also lead to kinds of pain that do not seem well-represented in other organisms, not all of which can be made sense of as biologically useful.

\section{III}

When exploring the conceptual space that surrounds the Christian doctrines of the fall and original sin, it is hard not to find oneself in Augustine's orbit, if only as a point of departure. In the opinion of many a Christian, and not just of the Orthodox stripe that never followed Augustine on these topics, Augustine is often thought to cause whatever trouble there may be with making sense of the terrain. Others don't see any difference between defending Augustine and defending a robust understanding of the Fall and its consequences. It is only fitting, then, that we return to the Bishop of Hippo for an insight that will allow us to launch our defense of the Fall.

Augustine takes up the Apostle Paul's distinction between physical and spiritual death, and he relates them to one another in a very particular way.

For instance, in the opening section of book thirteen of the City of God, he says,

The death, then, of the soul takes place when God forsakes it, as the death of the body when the soul forsakes it. Therefore, the death of both-that is of the whole man-occurs when the soul, forsaken by God, forsakes the body" (371)

But he later clarifies the interrelationships thus,

It may perhaps be supposed that because God said, 'Ye shall die the death,' and not 'deaths,' we should understand only that death which occurs when the soul is deserted by God, who is its life; for it was not deserted by God, and so deserted Him, but deserted Him, and so was deserted by Him. For its own will was the originator of its evil....But though...the words, 'In the day ye eat of it ye shall die the death,' should be understood as meaning, 'In the day ye desert me in disobedience, I will desert you in justice,' yet assuredly in this death the other deaths also were threatened, which were its inevitable consequence. For in the stirring of the disobedient motion which was felt in the flesh of the disobedient soul, and which caused our first parents to cover their shame, one death is experienced, that, namely, which occurs when God forsakes the soul. (This was intimated by the words He uttered, when the man, stupefied by fear, had hid himself, "Adam, where are thou?"-words which He used not in ignorance or inquiry, but warning him to consider where he was, since God was not with him.) (381)

On the one hand, Augustine thinks that physical death is the natural consequence of spiritual death, not an arbitrary punishment, and this is so because 
the relationship between God and the soul is analogous to the relationship between the soul and the body. On the other hand, Augustine seems to think that there is a redemptive or at least semiotic function that physical death can fill for us, namely, that it is an embodied symbol of spiritual death. This is much less obvious from the passage above. It is suggested by the interesting little remark Augustine makes about God's question to Adam and other places in the text such as his comments on why God does not free believers from physical death. The answer being, at least in part, that physical death is retained once spiritual regeneration has taken place for the good of the soul, because it is important for the growth of faith to remain under those conditions (cf. 373-374). ${ }^{3}$ Let's develop these themes one at a time, and in so doing, lay the foundation for a story of how the Fall is possible in connection with the biology of the last section.

For Augustine, God is to the soul as the soul is to the body. Just as the soul provides the order, identity, and purpose that allows a hunk of matter to be a human body, so too God provides the order, identity, and purpose of a human being, most directly by creating and sustaining the human soul. To put it in terms of Aristotelian causation, we aren't simply talking about efficient causation but formal causation, the distinction being close to the more contemporary distinction between causation and constitution. Something about the soul's relation to God not just historically but at any given moment gives it its distinctive kind identity. It makes it what it is and likewise for the soul and the body.

The parallel relationships between God, soul, and body, for Augustine, entail the following. Though it is not possible to sever one's relationship with God, one can damage it through sin. In so doing, one damages the relationship that gives one order, identity, and purpose. The soul will, therefore, not be able to perform its own functions the same way it would have if its connection to the divine were not damaged. One of those functions is imposing order, identity, and purpose on the body. Consequently, for Augustine, a natural consequence of a spiritual fall is a physical one in which the body is not as responsive to the soul's organizing efforts as it should be. This line of thought leads to some unintended comedy in Augustine, such as his suggestion that involuntary sexual arousal is a consequence of the Fall. The underlying thought is more interesting than some of Augustine's applications of it. Instead of thinking of the Fall as an arbitrary punishment inflicted by God, we are led to ask whether some of the effects associated with the Fall could be "organic" consequences of it, akin to the stomachache a child gets after eating too much candy.

This brings us to the second point. Physical death isn't just a natural consequence. It isn't just the natural endpoint of the biological process set in motion by spiritual alienation. It is also an embodied reality that depicts our spiritual condition in very tangible form. The fact that we will die is something we cannot escape from. It reminds us that we are mortal, that we are but creatures. It turns the mind outward to the question of whether there is any power out there that can save us from our certain (biological) death. For those who are heirs to the story of the Fall, it reminds us that our transgressions come at a cost. The spiritual problems that

\footnotetext{
${ }^{3}$ Likewise, Augustine's reflections on the presence of mortality throughout life (perhaps borrowed from Seneca) are suggestive of a medicinal function for our awareness of mortality (376-378).
} 
engender the Fall, of rejecting one's essential dependence on God and the context for human flourishing that God has set up, is directly checked by our constant background awareness that we are all destined for physical death.

Obviously, these points drawn forth from Augustine cannot be squared without adjustment with the picture of our past provided by evolutionary theory, but it is important to notice the following from Augustine's account. For Augustine, spiritual death is what is really important. Physical death, though a consequence of sin for him, is at least partly redeemed by the way in which God uses it as a kind of medicinal check on the bigger problem of spiritual death. God does this not through the biology of physical death but through the existential, moral, spiritual meaning that physical death has for us. God doesn't simply impose this meaning on physical death. For Augustine, the intimate connection between God, soul, and body lends itself, within the context of the Fall, to physical death acting as a check on and symbol of spiritual death.

Return then to the biology of pain canvassed in the previous section. There is a basic biological limiting system or a family of these, nociception, in even very basic creatures. The limiting system helps the creature flourish biologically and thus avoid premature death. Nociception in higher animals comes to have an affective overlay that interacts with more advanced rationality. This extends the range of the limiting system, allowing an animal to identify biological limits even when the proximal environment seems biologically friendly at a shallower level of processing. It also, however, creates a felt existential import for these biological limits that was not present for the simpler organism. The experience of limitation and the need to modify one's behavior in light of that limitation occupies more of a complex creature's time. Instead of simply reacting to proximal noxious stimuli in the moment, negative stimuli avoidance comes to dominate more of the creature's time and energy. Moreover, these developments, even though we are not yet on the level of human pain, lend themselves to a problem of evil discussion more than the nociception of simpler creatures. Though someone may be bothered by the idea that a good God would create biological organisms that can be harmed and must try to avoid harm to live, many wouldn't think we have a problem of evil to deal with until we have reason to think that nociception is paired with negative subjective experiences of the sort that would appear to come with more advanced biology.

In a higher mammal, one could say that pain, partly because it is experienced as bad, serves as an apt subjective symbol for an objective biological reality. The negative subjective feeling of pain serves the important biological function of drawing the creature's attention to the import of an objectively harmful feature of its environment and it does so because of the natural connection between the objective and subjective established by the constitution of the creature. The more biologically advanced a creature is the richer the subjective experiences made possible by its integrated cognitive and emotional systems.

These richer forms of subjective experience include more complex and varied emotional responses to potentially or actually harmful aspects of the environment. The evolution of the subjective experience of pain is relevant to moral experience and moral agency. One is put in a better position to appreciate the way that potential 
actions interface with our biological limits and those of others as well as the way those limits point to our mortality.

There is a resonance between the biological difference between the different kinds of pain-simple nociception, pain proper, and distinctively human pain - and what Augustine has to say about physical and spiritual death. This should not come as a surprise given that the distinction also lends itself to thinking about moral experience and agency. We can take advantage of this resonance to tell a story about how the Fall in Genesis 3, taken as myth, could be an apt way of depicting a literal fall.

Suppose that in God's providence, hominid evolution moved in the direction of producing beings with moral and spiritual agency. This required developments on both a cognitive and emotional level such that we could sustain the rich subjective experiences that come with such agency. These developments took up previous biological developments while extending, deepening, and adding to them. Just as the pain of higher animals took up more primitive nociception and endowed it with a subjective significance, so too these cognitive and emotional capacities took up previously developed biological systems and endowed them with new moral and spiritual experiential dimensions, including the human experience of pain.

The character of those experiences, however, was partly dependent on how these beings used their emerging capacities. God was not going to force these creatures to use them appropriately. Spiritual and moral agency well-used would lead to a peaceful awareness of God's providence and presence as well as a keen sense of how to live in harmony with one another and the broader order of nature. In particular, these beings could not use their new cognitive capacities to try to replace their essential dependence on God and the natural order God had put them in without suffering consequences. Without a breach of trust, they would experience pain merely as a biological limiting system with an important function in life. Similarly, physical death would be experienced simply as a transition to an afterlife, let us say. Living in harmony with one another and nature, they would not experience pain in excess of what was necessary biologically for a human life, and the prospect of and experience of physical death would not be attended by any untoward existential angst. ${ }^{4}$

Attempting to circumvent dependence on the divine, that is, attempting to use one's newfound rationality to create one's own order by bending nature and one's relationships to a self-interest defined independently of God's intentions or the common good, would have a series of implications. The relational rupture would render it difficult if not impossible to recapture one's prior sense of ultimate wellbeing. Instead, one's heightened rationality would make one hyper aware of one's inability to guarantee one's well-being as a finite creature acting on one's own. One would be aware of one's limits in a way a simpler creature could not be, especially the ultimate biological limit of physical death. A sense of one's creaturely finitude combined with this posture of self-dependence would clothe one's mortality in an existential dread that can be temporarily ignored but not forgotten. Moreover, living amongst others who have suffered the same rupture of relationship with the divine

\footnotetext{
${ }^{4}$ The pre-Fall species on this story might still be subject to pain that requires additional explanation, but it would be of a piece with the need to explain the biologically adaptive pain present in the animal kingdom generally.
} 
would lead to one's victimization at the hands of others who exploit one out of their rogue self-interest, which would only heighten one's anxiety and one's temptation to instrumentalize one's relationships with nature and other people in turn.

We can be flexible on exactly how the rupture happened. Here is one scenario, which we will elaborate partly because it requires so little by way of appeal to ingredients not already at the disposal of an evolutionary theorist. First, suppose that our species never attained an irenic, garden-dwelling state of vegan leisure. Rather, let's stipulate that the pre-Fall experience of the hominid population in question was much as it is for the higher primates of which we are aware. The hominids that become us are emerging from the state of relatively narrow self-interest modified by a basic pack mentality that we associate with higher animals that are not humans, and the opportunity to make the step into a more robust spiritual and moral agency becomes available.

For ease of explanation but also to explore the degree of isomorphism with Genesis possible, let's say that distinctive forms of human rationality become available to a particular male and female whom we'll go ahead and call Adam and Eve for convenience. On this story, Adam and Eve, instead of embracing this jump into fulfilled moral agency, freely return to the default self-interested behavior that is inculpable in animals. Due to Adam and Eve's new capacities, however, that turn is culpable and has existential implications for them. They are like young adults who culpably decide to keep acting like children, or perhaps like someone who's just been married who reverts to ways of thinking and acting that are only apt in someone who is unattached. Or, more likely, it could be worse than this. Using the rational and emotional ability that would have made it possible to transcend the old pack mentality instead to serve narrow self-interest would make it possible to transform the natural self-interest of a higher animal that is otherwise checked by the good of the pack into new forms of exploitive self-interest that have no place within the natural order God established.

Our hypothetical Adam and Eve fail to live up to their new capacities, but they do model new ways of acting that seem to lead to their dominance over scarce resources and to their domination of others in the hominid population. These behaviors then spread to their conspecifics as Adam and Eve act as cultural exemplars. Like trail guides, these most developed hominids through their choices determine the path of hominid cultural evolution at a critical juncture, in a way that their conspecifics and descendants cannot simply opt out of. Their choice is made possible by a long history of biological evolution, but the basic cognitive and emotional capacities that make possible moral and spiritual agency, once they arrive on the biological scene, are inherently susceptible to bad enculturation. They are vulnerable in this way in no small part because moral and spiritual agency rests on relational capacities and thus bad ways of relating can spread across the relational channels that are intrinsically necessary as part of the design of a creature meant to flourish through relationship.

Nothing precludes our positing that two (or more) hominids did, in fact, achieve a state of innocent exercise of robust agency before falling or positing that they lived in paradisal conditions. The scenario we've just sketched shows, however, that one can have a substantive and literal fall without these elements. Moreover, the 
scenario as we've sketched it makes the motivation for the first sin more intelligible than it usually is in stories about the Fall insofar as the default agency out of which the people in question were evolving provides the framework for culpable agency. To evolve in the direction of the human telos provided by God would involve rising above a self-interest that was necessary and unproblematic when married to sub-human rationality but culpable and destructive once we've made the evolutionary leap to humankind. It is in some ways easier to understand how we could come to the brink of fulfilled moral agency and fail to claim it by reverting to a pre-existing mindset than it is to imagine that we popped into being with the kind of agency God intended for us and then fumbled it away. Even if we are clear that Adam and Eve in Genesis depict a state of innocence not a state of perfection, the intelligibility of the moral failing is a benefit of the kind of Fall we've depicted in our story here.

Furthermore, one does not need a genetic bottleneck of two individuals in order for our scenario to work. If the Fall spreads by way of enculturation rather than genetic inheritance, then one only needs a bottleneck of such a size that a process of enculturation can reach each of the members of the emerging Homo sapiens population. It is not even necessary for enculturation to reach each member of the species in a short amount of time. As long as all the hominids that become us are reached eventually, the story works. A single inter-breeding population is sufficient for this and even distinct inter-breeding populations that have some cross-pollination at their fringes could, in principle, be subject to a single process of bad enculturation.

Would the Genesis myth about the Fall be a good fit with the scenario we've outlined? Could a story about a garden and a serpent really be an apt mythological way of conveying the theological upshot of our scenario? Consider some of the elements of the Genesis story. The temptation is cast in terms of a tree of knowledge and a serpent. Notice that the serpent's defining characteristic is that it is crafty. Instrumental rationality is highlighted from the serpent's first appearance, and the behavior of the serpent embodies an instrumental rationality divorced from any posture of trust or deference towards God. The serpent portrays the good of the knowledge offered by the tree in terms of not having to trust God's perspective. Instead, one can act so as to be able to determine oneself what is good and bad experientially. The action of taking the fruit of a forbidden tree and eating it symbolically conveys the idea of trying to provide for oneself in a way that violates the natural and moral order God has set up. The narrative stresses the way in which Eve evaluates the goodness of the fruit for herself in response to the temptation ("she saw that the fruit was good to eat and pleasing to the eye") as if this could provide a sufficient independent basis for a decision even though she already knows God has disallowed it. The serpent plants the thought that Eve could impose her own order on nature, in the form of pursuing knowledge of good and evil through the tree, without significant consequences. The serpent's message is that one can play God with nature and thereby make one's life better rather than worse, aptly capturing the way in which the re-application of higher forms of rationality to serve one's narrow selfinterests acts as an attempt to displace God.

The temptation in the Genesis narrative, in addition to being quite focused on knowledge, is also very concerned with death. Eve voices the idea that transgressing God's order would introduce death as a consequence. This gets reinterpreted in our 
story as pointing towards spiritual death and the reality that a spiritual rupture would lead to a different experience of physical death, and it is plausible that a myth could use death to stand in as a symbol of the experience of death. Incidentally, thinking of the concern with death not as biological perishing but rather in terms of the experience of mortality after spiritual alienation makes narrative sense of what is otherwise puzzling. In the narrative, we are led to believe that death is the punishment for eating from the tree, but the narrative has it that Adam and Eve don't conclude their earthly lives for a long while after the transgression. If, however, we're being too concrete in focusing on brain death or the cessation of homeostasis as the punishment, the puzzle goes away. An existential concern with mortality kicks in immediately in the wake of the transgression. Physical death sets in as an everpresent, existential concern even as the transgressors begin to experience spiritual death.

After succumbing to temptation, the first thing Eve does is pass along the behavior socially, handing the fruit to Adam, which, obviously, connects with the cultural contagion component of our story. The experience of sin leads to relational insecurity and rupture as seen in the experience of nakedness, which is again dealt with by imposing a new human-centric purpose on nature in the form of the fig leaves used to hide Adam and Eve's nakedness from God and one another. More fundamentally, Adam and Eve out of narrow self-interest and shame express and enact relational rupture by blaming everyone but themselves for their failure including not just one another and the serpent but God ("the woman you put here with me"). In the curses of the narrative, we see that the consequence is that the process of bearing and providing for future generations and relating to one another becomes shot through with negative experiences of physical and relational limitation as seen in the imagery of painful childbirth, labor as a struggle with an unyielding nature, and gender dynamics that mix love, longing, and domination. In short, though we do not claim that everything in the Genesis story is isomorphic to an element in the scenario we've depicted, there is a great deal of thematic resonance between the two such that we don't think it would be too far-fetched to say that the Genesis narrative could mythologically point towards an event or series of events like we have described.

One might well doubt whether our story can account for the aptness of at least one part of the Genesis myth, namely the cursing of creation. Our story has concerned humanity's experience of its own embodiment. Thus, one might think there is not much room for the idea that our fall would have outsize significance for other species or the earth itself. Consider, however, the thesis that the fall of our species (or our precursor species) had outsize impacts on the meaning of the pain and death of other, unrelated species. If the Fall has less to do with the introduction of death and pain than the experience of pain and death outstripping its intended function as a biological limiting system, then one can see how one species can exploit other species in a way so as to cause them pain from which they do not accrue appropriate biological goods. Think, for instance, of factory farming and the way in which humans can inflict pain and discomfort on other species that has very little biological utility for them. Alternatively, consider the way in which higher rationality decoupled from a willingness to submit to the natural order can lead to wanton destruction of habitat 
that, effectively, "curses" other species. Indeed, in an era of widespread concern about climate change, it has become all too plausible to think that the fall of our species has had implications for all creatures on earth, even if those effects have unfolded over the course of our species' career. ${ }^{5}$

If one was willing to make the link with the Genesis story a bit more impressionistic, nothing precludes assimilating the Fall to the more gradual timeline on which evolution is usually thought to work. Suppose that our spiritual and moral capacities emerge slowly over an extended period of time. Over this time of emerging agency, many individuals faced opportunities to become more trusting of and to act in greater harmony with God, nature, and one another. We can stipulate that some of those choices were made correctly, but on balance, emerging agents made selfish, isolating choices enough of the time to block any species wide benefit from whatever positive choices there may have been and to define a direction for the evolution of the species towards the morally conflicted and spiritually problematic state with which we are familiar. This long series of discrete events helps to shape the way that the human pain system attaches meaning to biological limitations. This more gradual change could well have both biological and cultural components depending on the timescale we're willing to countenance. On this alternative scenario, the Adam and Eve myth conveys in a digestible form the upshot of a long, complicated series of thousands upon thousands of choices made by a variety of agents with various kinds of capacities and interrelationships between them that nonetheless was morally and existentially equivalent for the species to a fundamental relational rupture with God at the species' formative origin.

If this more gradualist scenario feels like a questionable candidate for a literal Fall, consider an analogy. Think of the way political polarization can occur. Suppose we have a two-party system (for ease of illustration) whose parties are ideologically distinct but not extreme. It may even well be that the plurality of values that the political system tries to balance is such that it is almost inevitable that citizens will clump into two groups depending on their relative prioritization of political values. Nonetheless, let us say that the system is capable of working well if the two sides are well-matched and can work together. That's not how the story goes, however. Although certain political actions may be more potent than others, no single action on its own is likely to cause the two parties to veer to extremes. One can imagine, though, a series of attempts on both sides to gain short-term political capital by demonizing the other side which in turn makes a reach across the aisle less attractive, harder to execute, and less likely to be effective. In the meantime, each little rupture encourages one to define one's views in more stark terms to prove to one's base that one stands in clear contrast to the demonized and demonizing other. Even if there are isolated moments in which agents are motivated to or even try to achieve bipartisanship, there are enough polarizing political actions that the two sides gradually move

\footnotetext{
${ }^{5}$ One might still object that on our story "cursing" is not something God does so much as something we do to ourselves and other parts of creation. We are happy to accept the charge, though it should be noted that allowing someone to experience the consequences of their actions, though it may not be what we immediately think of when we think of someone being "cursed," nonetheless can be construed as a punishment. We thank a referee for bringing up this concern.
} 
towards political extremes that make bipartisan political actions the equivalent of "acting against nature". The effect will be relational rupture between citizens that prevents the achievement of the common good and creates existential threats and concerns that otherwise wouldn't exist even though the "political fall" in this case isn't a matter of one action creating polarization all at once. The same could be true for the Fall itself.

On both scenarios that we have outlined, one can invoke a version of the Augustinian line about how a good God might providentially use physical death to check our spiritual death. One could posit that God allows us to feel our biological, moral, and spiritual limits and works against our attempts to hide these limits from ourselves. The natural existential consequences of a rupture with God, self, neighbor, and nature when faced squarely act as an important check on human pretensions and create a foundational awareness of the need for grace. Human beings can, of course, resist this check in various ways-by hiding the old and the dying out of sight, ignoring evidence of ways that we have degraded the environment, living in artificial environments that provide the illusion of control, putting time and money into products and practices that promise to extend our biological peak artificially, explaining away personal and social ills in terms of situational and material factors that don't bear on any moral failing that might hit too close to home, etc. At the end of the day, however, it may be a divine mercy that these strategies are never completely effective. ${ }^{6}$

Notice that on both scenarios we have described we have appealed to rather uncontroversial mechanisms. Aside from positing the existence of God and the possibility of relationship with the divine, there is very little to the machinery of our stories that even a naturalist couldn't get on board with. The naturalist needs to posit that our evolutionary history was such as to endow us with moral and religious capacities that other animals don't seem to have and that our experiential life, though building on biological features we share with other species, nonetheless furnishes us with unique experiences that include a seemingly unique experience of mortality, some forms of pain, and relational ills. Likewise, it is a presumably neutral fact that human beings routinely fall short of the moral agency we think we have and that we are social creatures who can empower and disempower one another. This is not to say that a neutral party should be able to infer the Fall from the biology that's been appealed to in this article and whether a naturalist would be happy with our ruminations does not get to the heart of their adequacy. What we want to underline, however, is how much theological work we think can be done with thoroughly uncontroversial tools.

Consider, by contrast, defenses of the Fall by Peter Van Inwagen and Hud Hudson. It is not our intent to argue that their defenses are wrong or not philosophically worthwhile but rather to point out how svelte our theoretical

\footnotetext{
${ }^{6}$ As a referee helpfully pointed out, our gloss on the Fall has implications for one's doctrine of the atonement and potentially for how one thinks of the eschatological fate of creation. While we think this is true, we do not have space to develop this novel application of the views elaborated here. We note briefly and tantalizingly, though, that the idea that Christ models and invites us into a way of learning to live at peace within our limits as embodied creatures seems to us to have a lot of theological potential for Christology and soteriology.
} 
apparatus is by comparison. Van Inwagen posits that the Fall happened amongst a small group of early human primates who had been raised to rationality. Thus far, the story is like the one we have presented here, although we have given a naturalistically friendly gloss on what "raised" might mean. In addition, however, Van Inwagen posits that these primates were possessed of "preternatural powers" that allowed them to tame wild beasts with a look, cure disease with a touch, and intuit natural disasters in time to evade them (Van Inwagen 2006, 86). It is in light of these additions that he can claim that there "was thus no evil in their world," by which, of course, he means their experience of the world. Van Inwagen, in effect, inserts as much of a literal Genesis and the folklore that developed around it into evolutionary history as he can and then defends the claim that we don't know that these things couldn't have happened in this way. The more fanciful elements of his story would be unnecessary, however, if he had a way of preserving a fall without having to exclude physical pain and death from the realm of these early hominids which is what our story drawing on the biology of pain allows us to do.

Hud Hudson, for his part, invokes hypertime as a possible explanation of the Fall (Hudson 2014). If, from a meta-perspective, God can re-order the time slices or causal relations between time slices in our universe, perhaps, the thought goes, we could have a literal Adam and Eve committing a sin at some formative time in Earth's history but then Adam and Eve could be spliced post-fall into a time slice more appropriate for finding human beings within evolutionary orthodoxy. This would allow the Fall in Genesis to be construed as literally true so far as it goes. The telling of the Fall in Genesis would leave out something important, namely God's creative shuffling of the deck of spacetime planes (or sub-regions thereof), but maybe that would have been hard to communicate. This strategy for rendering the Fall and evolution consistent would have the potential benefit of allowing the Fall to be responsible for animal pain as with the traditional, non-mythological read of Genesis. Our account cannot claim that feature. Hudson's story, however, requires not only accepting the coherence of hypertime but also accepting that God would arrange hypertime so as to create a relationship amongst time slices that only the need to defend the Fall against evolutionary biology would lead anyone to think of. ${ }^{7}$

By way of contrast, nothing in our two scenarios requires a departure from common sense metaphysics (or its affirmation for that matter). The pre-Fall state of humanity does not need us to posit anything magical about it. Our stories rely simply on the biology of pain and the relatively banal posit that what we do with our agency, whether due to a choice made at an important developmental fork in the road or due to a series of choices made over time, can affect our experience of the world and the experiences of others. Our two stories of the Fall are sufficient to defend the claim

\footnotetext{
${ }^{7}$ Likewise, although it concerns a different, though related, issue, consider Mike Rea (2007) who, taking a cue from Jonathan Edwards, argues that we are spacetime worms extended through four dimensions but that God gets to decide what spacetime worms count as subjects of moral evaluation. God, then, can decide to treat all humans as parts of a single thing, the human species, and hold it responsible for the sin of Adam. This move requires accepting four dimensionalism and a certain view of human identity in a four dimensionalist framework, while yet also requiring that one employ that metaphysical apparatus once again in a way that no one would think to do were they not defending doctrines related to the Fall against objection.
} 
that the Fall can still do important theodical and soteriological work, indeed that it can still do as much work as was reasonable to have expected it to do before the advent of evolutionary theory.

Finally, our tale has some features that are reminiscent of the Irenaean approach to the Fall that has seen some resurgence in contemporary reflections (cf. Schneider 2012; De Cruz \& De Smedt 2013; Hick 1966). Re-habilitations of Irenaeus usually emphasize the idea that early human beings were developmentally immature and human beings were meant to undergo a developmental process. Our account can preserve the gradualist elements of the Irenaean approach and its openness to God's creation plan being dynamic rather than static. The intelligibility of a Fall that happens to agents who are not perfect but are, in a sense, immature carries over. At the same time, there is a potential in rehabilitations of Irenaeus to so emphasize the immaturity of our ancestors and the gradualist providence of God that it ceases to be clear whether the Fall is really much of a fall as opposed to just a developmental phase. ${ }^{8}$ A Fall that isn't a fall, however, can't fill the theodical and soteriological functions that give the doctrine its theological point. By way of contrast, though we carry over many of the attractive features of an Irenaean approach, we preserve the idea that the Fall was a relational rupture that is deeply explanatory of the negative elements of the human condition such that it is important that we and not God are responsible for those elements and that the human condition makes intelligible the universal human need for salvation. The process may be developmental in a sense, but development can be de-railed in a way that helps to explain the need for a relational intervention.

In conclusion, in this paper, we gave a defense of the doctrine of the Fall and its capacity to do essential theodical and soteriological work by appealing to both the biology of pain and Augustinian insights into the relationship of physical and spiritual death. If we think of pain as, biologically, a limiting system but one that interacts with advanced rationality in such a way as to create a new experience of one's biological limits, then one can use Augustine's treatment of our experience of physical death as both a consequence of and a symbolic check on our moral and spiritual condition to give an account of the Fall. This story of the Fall uses relatively uncontroversial materials to tell a story that nicely fits the literary and thematic dimensions of the Genesis story.

\footnotetext{
${ }^{8}$ It should be noted, as a referee pointed out to us, that there is reason to believe that re-habilitations of Irenaeus may tend to highlight what is unique about Irenaeus at the expense of substantial points of continuity with Augustine on these topics (cf. McCoy 2014).
} 


\section{References}

Alupay, Jean S.; Stavros P. Hadijsolomou; and Robyn J. Crook. 2014. "Arm Injury Produces Long-Term Behavioral and Neural Hypersensitivity In Octopus." Neuroscience Letters 558(13):137-42.

Augustine. 2013. City of God. Trans. Marcus Dods. Peabody, Mass.: Hendrickson.

Bateson, Patrick. 1991. “Assessment of pain in animals.” Animal Behavior 42(5):827-839.

Broom, Donald. 2001. "Evolution of Pain." In Pain: Its Nature and Management In Man and Animals, edited by E. J. L. Lord Soulsby, and D. Morton, 17-25. Royal Society of Medicine International Congress Symposium Series (Vol. 246). London, U.K.: Royal Society of Medicine.

Crook Robyn J.; Trevor Lewis; Roger T. Hanlon; and Edgar T. Walters. 2011. "Peripheral Injury Induces Long-Term Sensation Of Defensive Responses to Visual and Tactile Stimuli In the Squid Loligo Pealeii, Lesueur 1821." Journal of Experimental Biology 214(19): 3173-85.

Crook, Robyn J.; Roger T. Hanlon; and Edgar T. Walters. 2013. "Squid Have Nociceptors That Display Widespread Long-Term Sensitization and Spontaneous Activity After Bodily Injury." Journal of Neuroscience 33(24): 10021-6.

De Cruz, Helen and Johan De Smedt. 2013. "Reformed and Evolutionary Epistemology and the Noetic Effects of Sin." International Journal for the Philosophy of Religion 74(1): 49-66.

Hick, John. 1966. Evil and the God of Love. London: MacMillan.

Hudson, Hud. 2014. The Fall and Hypertime. New York: Oxford University Press.

Jensen, Troels S. and Nanna B. Finnerup. 2014. "Allodynia and Hyperalgesia In Neuropathic Pain: Clinical Manifestations and Mechanisms." Lancet Neurology 13(9): 924-35.

Kooijman Carolien M.; Pieter U. Dijkstra; Jan H. B. Geertzen; Albert Elzinga; and Cees P Van der Schans. 2000. "Phantom Pain and Phantom Sensations In Upper Limb Amputees: An Epidemiological Study.” Pain 87(1):33-41.

Limakatso Katleho; Gillian J. Bedwell; Victoria J. Madden; and Romy Parker. 2019. "The Prevalence of Phantom Limb Pain and Associated Risk Factors In People With Amputations: A Systematic Review Protocol.” Systems Review 8(1):17.

MacDonald, Scott. 1998. "Primal Sin." In The Augustinian Tradition, edited by Gareth Matthews, 110-139. Berkley: University of California Press.

McCoy, Andrew. 2014. "Becoming Who We Are Supposed to Be: An Evaluation of Schneider's Use of Christian Theology in Conversation With Recent Genetic Science." Calvin Theological Journal 49(1):63-84. 
McFarland, Ian. 2010. In Adam's Fall: A Meditation on the Christian Doctrine of Original Sin. Malden, Mass.: Wiley Blackwell.

Murray, Michael. 2008. Nature Red in Tooth and Claw: Theism and the Problem of Animal Suffering. New York: Oxford University Press.

Nagasako, Elna M.; Anne Louise Oaklander; and Robert H. Dworkin. 2003. "Congenital Insensitivity to Pain: An Update." Pain 101(3): 213-219.

Noonan, James P. 2010. "Neanderthal Genomics and the Evolution of Modern Humans." Genome Research 20 (5): 547-553.

Patriquin, Logan. 2019. Testing the Homiletical Buoyancy of James K. A. Smith's 'Narrative Arc' Approach to the Fall." The Asbury Journal 74(1): 171-182.

Rea, Michael. 2007. "The Metaphysics of Original Sin.” In Persons: Human and Divine, edited by Peter Van Inwagen and Dean Zimmerman, 319-356. New York: Oxford University Press.

Ruse Michael and Joseph Travis. 2009. Evolution: The First Four Billion Years. Cambridge, Mass.: Belknap Press.

Rutherford, Kenny M.D. 2002. "Assessing Pain In Animals." Animal Welfare 11(1): 3153.

Schlebusch Carina M.; Helena Malmström; Torsten Günther; Per Sjödin; Alexandra Coutinho; Hanna Edlund; Arielle R. Munters; Mario Vicente; Maryna Steyn; Himla Soodyall; Marlize Lombard; and Matthias Jakobsson. 2017. "Southern African Ancient Genomes Estimate Modern Human Divergence to 350,000 to 260,000 Years Ago". Science 358 (6363): 652-655.

Schneider, John. 2012. “The Fall of 'Augustinian Adam': Original Frailty and Supralapsarian Purpose.” Zygon 47(4): 949-969.

Smith, James K. A. 2017. "What Stands on the Fall? A Philosophical Exploration." In Evolution and the Fall, edited by William Cavanaugh and James K. A. Smith, 4864. Grand Rapids: Eerdmans.

Smith Ewan and Gary Lewin. 2009. "Nociceptors: A Phylogenetic View." Journal of Comparative Physiology 195(12): 1089-1106.

Sneddon, Lynne U.; Robert W. Elwood; Shelley A. Adamo; and Matthew C. Leach. 2014. "Defining and Assessing Animal Pain." Animal Behaviour 97:201-212.

Stringer, Chris. 2003. "Human Evolution: Out of Ethiopia." Nature 423(6941): 692-695.

Van Inwagen, Peter. 2006. The Problem of Evil. New York: Oxford University Press.

Walters, Edgar T. 2018. "Nociceptive Biology of Molluscs and Arthropods: Evolutionary Clues About Functions and Mechanisms Potentially Related to Pain." Frontiers in Physiology 9: 1049. 